\title{
Errata
}

\section{New Synthesis of a Pyrroloquinoline Skeleton, the Martinelline Core, Using a Tandem Michael-Aldol Strategy}

Osamu Hara, Kazuhiko Sugimoto, Kazuishi Makino, Yasumasa Hamada* Synlett, 2004, 1625.

The formal synthesis of martinelline, by a route very different from that we described, has been published and should be included as Reference (3) part (f) on page 1627.

References

(3) (f) Takeda, Y.; Nakabayashi, T.; Shirai, A.; Fukumoto, D.; Kiguchi, T.; Naito, T. Tetrahedron Lett. $2004,45,3481$.

The author apologizes for this omission. 